\title{
Nutritional Status and Associated Risk Factors Among Adolescent Girls in Agarfa High School, Bale Zone, Oromia Region, South East Ethiopia
}

\author{
Ahmed Yasin Mohammed ${ }^{1, *}$, Tomas Benti Tefera ${ }^{2}$ \\ ${ }^{1}$ Department of Public Health, College of Medicine and Health Science, Madawalabu University, Bale Goba, Ethiopia \\ ${ }^{2}$ Department of Nursing, College of Medicine and Health Science, Madawalabu University, Bale Goba, Ethiopia
}

Email address:

ahmedyassinmoha@yahoo.com (A. Y. Mohammed)

To cite this article:

Ahmed Yasin Mohammed, Tomas Benti Tefera. Nutritional Status and Associated Risk Factors Among Adolescents Girls in Agarfa High School, Bale Zone, Oromia Region, South East Ethiopia. International Journal of Nutrition and Food Sciences.

Vol. 4, No. 4, 2015, pp. 445-152. doi: 10.11648/j.ijnfs.20150404.15

\begin{abstract}
Adolescent have typically been considered as low risk for poor health and often receive few health care resource and attention. However, their approach ignores the fact that many health problems later in life can be improved by adopting health life style habits in adolescents. There is a shortage of studies about nutritional status and associated factors among adolescent girls. The objective of this study was to asses nutritional status of adolescent girls and associated factors in Agarfa high school, Bale zone, Oromia Region, south Eastern Ethiopia. Institutional based cross sectional study was conducted to assess nutritional status of and associated factors in adolescent. The sample size was calculated based on the single proportion formula using the prevalence of malnutrition in adolescents $27 \%, \alpha=5 \%$ and degree of margin of error $5 \%$. The final sample size was 212 adolescent girls. The study employed systematic sampling technique to select adolescents and the data were collected by using structured questionnaire. Descriptive statistics was used for reporting the different characteristics while chi square test will be employed to determine factors associated with nutritional status. In this study it can be concluded that the prevalence of underweight and overweight is high. This indicates the double burden of malnutrition among adolescent girls in this area. Dietary factors such as meal frequency, meal skipping and dietary diversity were the associated factor for nutritional status of adolescent girls. Appropriate nutrition education intervention should designed to improve the nutritional status of adolescents girls.
\end{abstract}

Keywords: Nutritional Status, Risk Factors, Adolescents Girls

\section{Introduction}

Adolescence is an intense anabolic period when requirement for all nutrients increases. Between 11-19 years of age young people undergo rapid changes in body structure and physiologic, psychological and social functioning. Hormones set with these development agenda together with social structure designed to foster the transition from childhood to adulthood. Adolescent passes through three distinct periods: early (11-13), middle (14-16), and late (1719). Each marked by characteristics set of biologic, psychological and social issues [1].

During adolescence, $20 \%$ of final adult height and $50 \%$ of adult weight are attained, bone mass increases of $45 \%$ dramatic bone remodeling occur and soft tissue, organs and even red blood cell mass increase in size. This situation is further complicated when adolescents are often exposed to infection and parasite that can compromise nutritional status [2].

Adolescent has typically being considered as low risk of poor health and often receive few health care source and scant attention. However, this approach ignores the fact that many health problems later in life can be improved by adapting health life style habit in adolescents. Even though the problem is widely distributed, thus are only few studies regarding the level of malnutrition in some area of country[3].

There is little information about the nutritional status of adolescents. Resources have traditionally been directed at young children and pregnant women. So adolescent nutrition is suffering from lack of data; low policymaker interest in the nutritional problems of adolescents; little program experience; and the shortage of resources-contribute to a critical lost 
opportunity to strengthen the health, development, and economic progress of nations.

Since one of the millennium development goals is reduction of maternal mortality, this study will give in-sight for nutritional status in adolescent girls which has significant impact on their future life. In view of the fact that, the tomorrow's mothers are the current adolescent girls, the study has its part for the policy makers and implementers to work on prevention of adolescent malnutrition.

\subsection{Significance of the Study}

Malnutrition is widely spread problem affecting people who are found in all corners of the world, including both the developed and developing countries. But the problem is mostly prevalent in developing countries like Ethiopia, even though many governmental and nongovernmental organizations are striving to decrease the prevalence. Problem of malnutrition is currently existing problem. Prioritizing one extreme of malnutrition over the other is difficult on limited budget. But under nutrition continues to be the main focus of research health care spending. Adolescent nutrition receives very little attention and difficult to quantify accurately in this age group due to rapid change in growth and development and lack of consensus over which definition to use. Problem of malnutrition needs collaborative effort planners, policy makers and the community at large.

Therefore findings of this study will contribute baseline data on the issue and will elicit support and promote cooperation among the different stakeholders towards the initiation of a sustainable nutrition and health promotion program for adolescent girls in Agarfa town.

Adolescence is the second most critical period of physical growth in the life cycle after the $1^{\text {st }}$ year. Twenty five percent of adult heightened during adolescence. For many adolescents inadequate quality and quantity of food are the prime determinant of nutritional problems. These conditions may be due to household food insecurity, intra household allocation that does not meet their full range of dietary needs, livelihood insecurity and lack of nutritional knowledge. Micro nutrient malnutrition and chronic energy deficiency resulting in thinness (low BMI). BMI is a measure of thinness in adolescents and adults. It is equal to persons height in kilogram $(\mathrm{kg})$ divided to height in meter square $\left(\mathrm{m}^{2}\right)$ and stunting stem primarily from poor diet. Excessive physical activity patterns (example heavy workloads and walking long distance) and infection may contribute to under nutrition[13]

Stunting (short stature) in both adolescent boys and girls was prevalent in 9 and 11 students conducted by the international center for research in women in the early 90 's ranging from $27 \%$ to $65 \%$. Data on underweight (thinnest indicated by low BMI for adolescent and adults) are largely available. ICRW reported low BMI ranged from 3 to $53 \%$. Adolescents in India, Nepal and Benin were the most severely affected among the 11 study sites. Over weight (obesity) data are not widely reported for adolescents, but there is growing concern about these populations. WHO estimates that $60 \%$ of deaths globally are due to non communicable diseases associated with unhealthy diet and physical in activity, with $79 \%$ of these deaths occurring in developing countries [14].

The same changes in diet in physical activity contribute in the increased prevalence of in growth, often seen side by side in communities with under nutrition. There is also some evidence that low birth weight may predispose individuals to obesity and associated chronic disease later in life. In child $12 \%$ school children are obese, $17 \%$ of older adolescent girls in South Africa are obese and in china, one study found that the prevalence of overweight and obesity (BMI $>25 \%)$ in young adult has moved up from $10 \%$ to $15 \%$ for urban areas and from $6 \%$ to $8 \%$ in rural areas over 10 years period (19821992 G.C) [13]

\subsection{Investing in the Nutritional Status of Adolescents the Cost of Non Intervention}

Information on the economic returns to various types of investment in youth development is scarce, but recent cost benefit analysis for nutritional supplementation of secondary school estimated to benefit cost ratio between 26 and 45 depending on the assumption. We know something about the cost non investment. For e.g. it is estimated that for every $\mathrm{Kg}$ less of weight at birth, an American child achieve 15\% less in adult earning over his/her life time. The average life time cost of care a child born with neural tube defect in the United States is over $\$ 500,000$. In setting with high incidence by 13 IQ points defects in adult height result in productivity losses. In Philippines, a $1 \%$ deficit was associated with a $1.35 \%$ loss in agricultural wages[13].

The objective of this study is to assess nutritional status and associated factor among adolescent adolescents in Agarfa high school, Bale zone, Ethiopia.

\section{Methodology}

\subsection{Study Area and Period}

The study was conducted in Agarfa town high school which is $31 \mathrm{Km}$ away from Robe and 465 from the capital Addis Ababa. It has a total area of 40 hectares. It has one Kebele with average total population of 25,675. From these males are 12,370 and females are 13,305. The town has one health center and health post. According to woreda health office estimation the proportion of population accessible to safe water, toilet and refusal disposal are $61.8 \%, 86.3 \%$, $29.5 \%$ respectively. The study was conducted from May $10-$ $15 / 2014$

\subsection{Study Design}

Institutional based cross sectional design was employed.

\subsection{Source Population}

All female adolescents (11-19) in the Agarfa high school were the source population 


\subsection{Study Population}

Randomly selected female adolescents in the high school were the study population.

\subsection{Inclusion Criteria}

Female adolescents who were in the age of 11-19 years in Agarfa high school.

\subsection{Exclusion Criteria}

Adolescents who are not volunteer to be interviewed, Adolescents who have deformed anthropometric appearances and Adolescents who are pregnant at the time of data collection. Female adolescents who were absent at time of data collection.

\subsection{Sample Size Determination}

A single proportion formula was used to determine the sample size. Proportion of malnutrition in adolescents girls which was about $27 \%$ (16), confidence level of $95 \%$ with $5 \%$ marginal error used.

$$
\mathrm{n}=(\mathrm{z} \alpha / 2)^{2} \mathrm{p}(1-\mathrm{p}) / \mathrm{d}^{2}
$$

Where, $\mathrm{Z}=1.96$ (confidence interval at $95 \%$ )

Then the final sample size became 212 .

\subsection{Sampling Procedure (Technique)}

There are two governmental schools, one elementary school and one preparatory school in Agarfa town. The study will be conducted in Agarfa high school in female adolescents. Total number of students (female student) will be identified through reviewing records in director office. Number of female students to be included in the study is determined by systematic random sampling method. By using systematic random sampling method, every $3^{\text {rd }}$ female students were included and an interview was continued until required sample size is obtained.

\subsection{Data Collection Method}

A questionnaire adapted from the national nutrition survey was used to collect the data. Anthropometric measurement was used to measure weight and height of adolescent using bath room scale (detecto medic). It has ability to measure weight from 0 to $140 \mathrm{Kg}$. Height was measured by using standing height. To measure height, subject should wear light shoes and eye should be looking straight ahead (Frankfurt plane). MUAC was measured by marking midway between acromion (shoulder) and the olecranon (elbow) on the vertical axis of the upper arm with the arm bent at right angle and between the lateral and medial surface of the arm.

\subsection{Data Quality Control}

Five data collector students who are final year health officer students were recruited and trained to collect data. Training was given on how to interview, fill questionnaire and how to make anthropometric measurements.

\subsection{Data Analysis}

Descriptive statistics (frequency mean, median) was used for description of findings while chi square test was used to see associated factors for nutritional status. Data were summarized and presented in tables and graphs.

\subsection{Ethical Consideration}

Before data collection ethical clearance was obtained from Madawalabu University College of Medicine and Health Science ethical committee and Verbal consent was obtained from the respondents and they were assured about the confidentiality of the information.

\section{Result}

\subsection{Demographic and Socio-Economic Characteristics}

Table 1. Socio demographic characteristics of female adolescents in Agarfa High school, Bale zone, Oromia Region, Ethiopia, June, 2014.

\begin{tabular}{llll}
\hline Variables & & Frequency & Percentage \\
\hline \multirow{2}{*}{ Age } & $11-14$ years & 4 & 1.88 \\
Marital status & $15-19$ years & 208 & 98.12 \\
& Single & 209 & 98.58 \\
Religion & Married & 3 & 1.42 \\
& Muslim & 120 & 56.60 \\
& Orthodox & 77 & 36.33 \\
Ethnicity & Protestant & 15 & 7.07 \\
& Oromo & 156 & 73.58 \\
Educational status & Amhara & 51 & 24.05 \\
& Tigire & 5 & 2.37 \\
Place of residence & $10^{\text {th }}$ grade & 81 & 61.79 \\
& Urban & 135 & 38.21 \\
& Rural & 77 & 63.68 \\
Family size & $<5$ & 45 & 36.32 \\
& $5-10$ & 148 & 21.23 \\
Monthly family & $>10$ & 19 & 69.81 \\
income & $<500$ birr & 21 & 8.96 \\
& $500-1000$ birr & 55 & 9.91 \\
\hline \multirow{2}{*}{ the } & 136 birr & & 25.94 \\
& & 64.15 \\
\hline
\end{tabular}

From a total of 212 samples who were obtained $4(1.88 \%)$ are in early adolescence $(11-4)$, while $208(88.12 \%)$ were in late adolescence (15-19). About 209 (98.58\%) were singe while $3(1.42 \%)$ were married. About $120(56.60 \%)$ were Muslims, 77(36.33\%) were orthodox and 15 (7.07\%) were protestant by religion. About $156(73.58 \%)$ were Oromo, 51(24.05\%) were Amhara and 5(2.37\%) were Tigre. About $131(61.79 \%)$ were from grade 9 while $38.21 \%$ (81) were from grade 10 . About $63.68 \%$ (135) were living in urban area while $36.32 \%$ (77) were giving in rural area. About 45 $(21.23 \%)$ of the students constitute a family size less than 5 . About $148(69.81 \%)$ of students constitute a family size between 5 and 10 , while $19(8.96 \%)$ of the students constitute a family size of greater than 10 . About $183(86.33 \%)$ of the students were using pipe water, 25 (11.79\%) were using river 
water, 2(0.94\%) were using spring and well water. About 136 $(64.15 \%)$ the students were from the family those their monthly income is greater 1000 birr, 55(25.94\%) were from the family those their monthly income is between 500 to 1000 birr while $21(9.91 \%$ ) are from those their monthly income is less than 500 birr (Table 1).

\subsection{Behavioral Related Characteristics, Nutrition and Diet Information}

Neither of the adolescents had been pregnant nor lactating mothers. All of the adolescents reported that all had started menstruation. All of the respondents reported that they wash their hand always before meal and after toilet. Neither of the respondents reported that they had chat chewing, cigarette smoking and alcohol consumption. Among the adolescents about $32(15.09 \%)$ experienced disease in the last two weeks. About $76.89 \%$ (163) have information on nutrition and $23.11 \%$ (49) have no information on nutrition. From those who have information on nutrition. About $67.48 \%$ have got information from school, $20.85 \%$ were from TV, 9.22\% were from radio and $2.45 \%$ were from their parents. For $92(43.39 \%)$ of the adolescent girls their staple food is teff, for $71(33.49 \%)$ their staple food is wheat, for $41(19.34 \%)$ their staple food is Barley and for $2(0.95 \%)$ their staple food was sorghum (Figure 1).

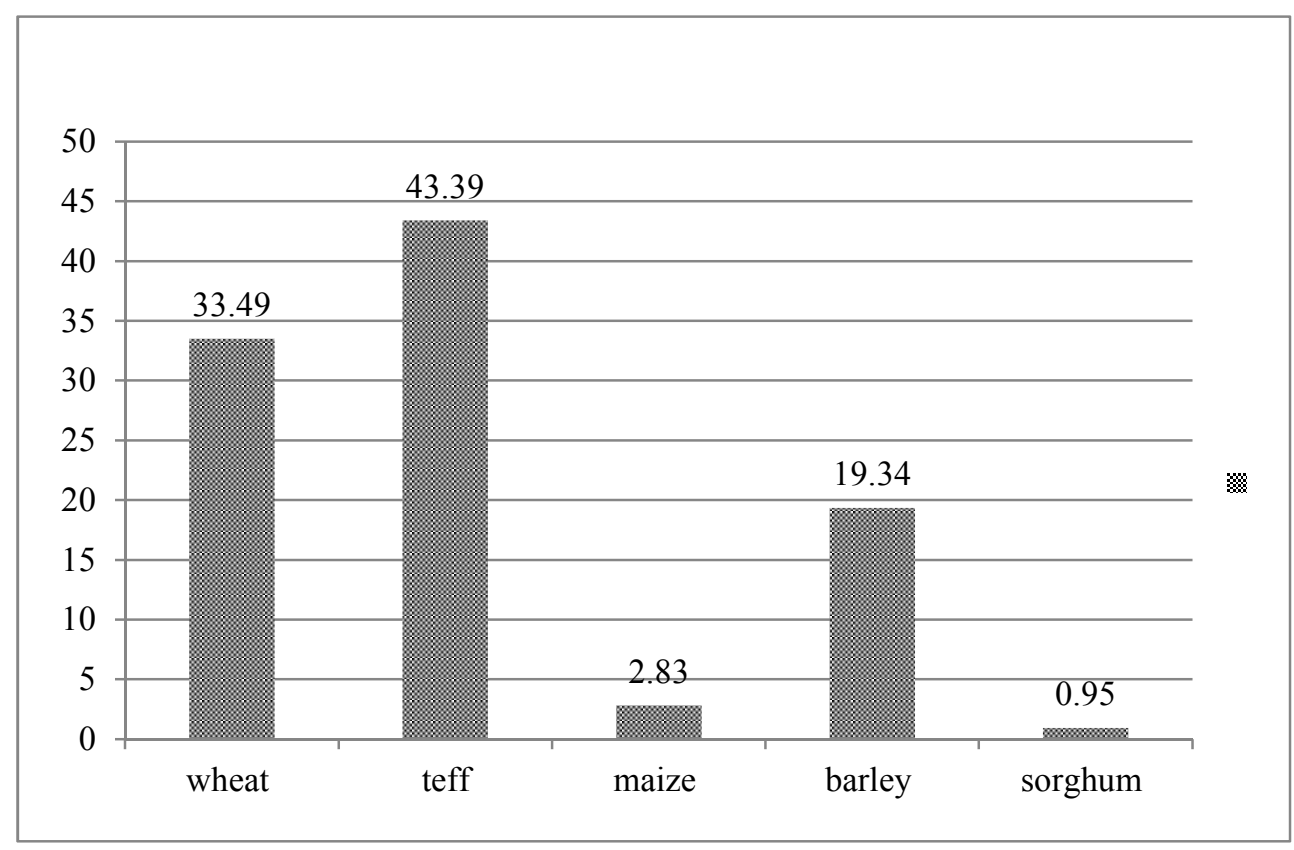

Figure 1. Staple foods of the adolescents in Agarafa town, Bale zone, Oromiya region, 2013.

Most of the adolescents (79.72\%) had usual diet of injera bread (Figure 2). while about 16.98 of them reported that their usual diet is

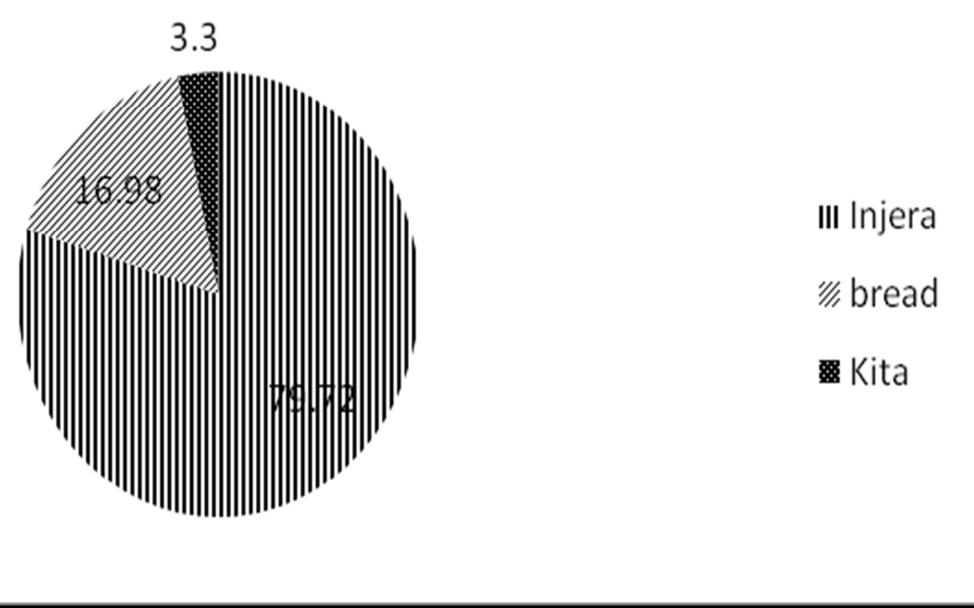

Figure 2. Usual diet of respondents among adolescents in Agarfa town, Bale Zone, Oromia region 2014.

About 193(91.03\%) of the adolescents ever take contraceptives. Most of the adolescents 175(82.55\%) had a frequency of meal 3 times per day while about5(2.36\%) had only 2 times per day. About 105 (49.53\%) of the students 
were skipped their regular meals in the last two weeks during the data collection (Table 2).

Table 2. Behavioral related characteristics of female adolescents in Agarfa High school, Bale zone, Oromia region, Ethiopia, June, 2014.

\begin{tabular}{llll}
\hline Variable & & Frequency & Percentage \\
\hline $\begin{array}{l}\text { Have you ever taken } \\
\text { contraceptives }\end{array}$ & Yes & 19 & 8.97 \\
& No & 193 & 91.03 \\
Number of meals eaten per day & $2^{\mathrm{x}}$ & 5 & 2.36 \\
& $3^{\mathrm{x}}$ & 175 & 82.55 \\
Do you skip any regular meal in & $4^{\mathrm{x}}$ & 32 & 15.08 \\
the last two weeks & yes & 105 & 49.53 \\
\hline
\end{tabular}

$\mathrm{x}$ times

About $154(72.6 \%)$ of the adolescents ate cereal based foods, while $54(25.5 \%)$ of the adolescents ate legumes for 5 days and above in the last week About 15.6\%, 27.4\%, 8.5\% of adolescents ate vegetables, animal products and are root crops respectively for 5 and above days in the last week during the data collection (Table 3 ).
Table 3. Food items consumed in the last week in number of days of female adolescents in Agarfa High school, Bale zone, Oromia Region, South Eastern Ethiopia, June 2014.

\begin{tabular}{llll}
\hline Variable & & Frequency & Percentage \\
\hline \multirow{2}{*}{ Cereal based food } & $<5$ days & 58 & 27.4 \\
& $\geq 5$ days & 154 & 72.6 \\
Legumes & $<5$ days & 158 & 74.5 \\
& $\geq 5$ days & 54 & 25.5 \\
Fruits & $<5$ days & 194 & 91.5 \\
& $\geq 5$ days & 18 & 8.5 \\
Vegetables & $<5$ days & 179 & 84.4 \\
Animal products & $>5$ days & 33 & 15.6 \\
Roots and tubers & $\geq 5$ days & 154 & 72.6 \\
Root crops & $<5$ days & 58 & 27.4 \\
& $>5$ days & 194 & 91.5 \\
\hline
\end{tabular}

This study found that $171(80.7 \%)$ of the adolescents fulfilled the minimum WHO dietary diversity according to the 24 recall. But about 41(19.3\%) of the adolescents did not the minimum $\mathrm{O}$ criteria for food diversity (Figure 3).

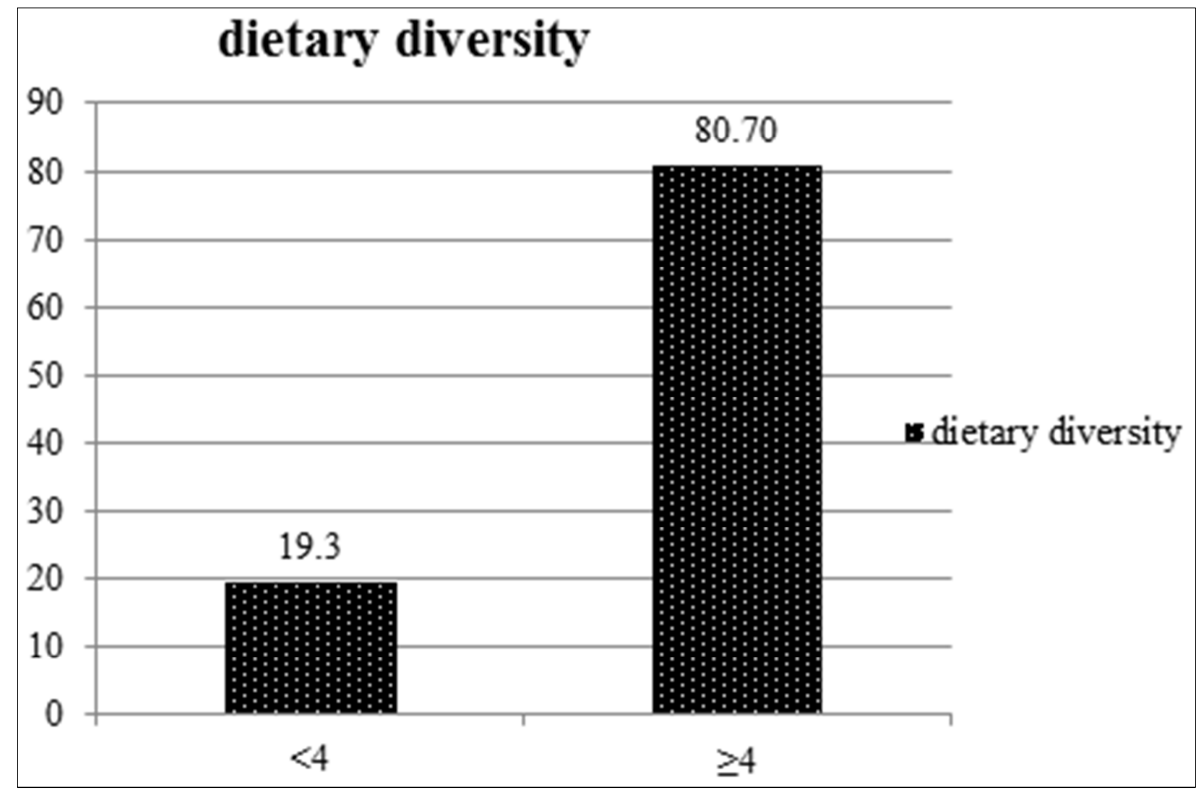

Figure 3. Prevalence of minimum dietary diversity among adolescents in Agarfa Town, Oromia region, Bale Zone, 2014.

\subsection{Nutritional Status of Adolescent Girls}

Table 4. Anthropometric measurements of female adolescents in Agarfa High School, Bale zone, Oromia region, Ethiopia, June 2014.

\begin{tabular}{llll}
\hline Variables & & Frequency & Percentage \\
\hline \multirow{2}{*}{ BMI } & $<18.5 \mathrm{~kg} / \mathrm{m}^{2}$ & 29 & 13.68 \\
& $18.5-24.9 \mathrm{~kg} / \mathrm{m}^{2}$ & 164 & 77.36 \\
& $>25 \mathrm{~kg} / \mathrm{m}^{2}$ & 19 & 8.96 \\
MUAC & $<13 \mathrm{Cm}$ & 0 & - \\
& $\geq 13 \mathrm{Cm}$ & 212 & 100 \\
\hline
\end{tabular}

This study found that about 29 (13.68\%) of the adolescents were underweight while most of the adolescents $164(77.36 \%)$ were normal according to BMI. The prevalence of overweight was 19(8.96\%) among adolescents in Agarfa town. However according to the MUAC assessment none of the adolescents were found malnourished (Table 4).

\subsection{Associated Risk Factors of Nutritional Status}

The chi square analysis showed that monthly income $(\mathrm{p}<0.05)$, number of meals per $\operatorname{day}(\mathrm{p}<0.01)$, meal skipping $(p=0.01)$, diet diversity $(p=0.05)$ were the associated factors for nutritional status However place of residence, family size and usual diet were not the associated factors (Table 5). 
Table 5. Associated Factors of Nutritional status (BMI) among adolescents in Agarfa High School Bale Zone Oromia Region June 2014.

\begin{tabular}{|c|c|c|c|c|c|c|c|}
\hline \multirow{2}{*}{ Variable } & & \multicolumn{3}{|l|}{ BMI } & \multirow{2}{*}{ Total } & \multirow{2}{*}{$\mathbf{X}^{2}$} & \multirow{2}{*}{ P. Value } \\
\hline & & Under Weight & Normal & Overweight & & & \\
\hline \multirow{3}{*}{ Residence } & Urban & 17 & 104 & 14 & 135 & \multirow{3}{*}{1.12} & \multirow{3}{*}{$>0.2$} \\
\hline & Rural & 12 & 60 & 5 & 77 & & \\
\hline & Total & 29 & 164 & 19 & 212 & & \\
\hline \multirow{4}{*}{ Religion } & Muslim & 16 & 91 & 13 & 120 & \multirow{4}{*}{1.63} & \multirow{4}{*}{$>0.2$} \\
\hline & Orthodox & 10 & 62 & 5 & 77 & & \\
\hline & Protestant & 3 & 11 & 1 & 15 & & \\
\hline & Total & 29 & 164 & 19 & 212 & & \\
\hline \multirow{4}{*}{ Ethnicity } & Oromo & 23 & 116 & 17 & 156 & \multirow{4}{*}{4.29} & \multirow{4}{*}{$>0.2$} \\
\hline & Amarha & 6 & 43 & 2 & 51 & & \\
\hline & Tigire & 0 & 5 & 0 & 5 & & \\
\hline & Total & 29 & 164 & 19 & 212 & & \\
\hline \multirow{4}{*}{ Family size } & $<5$ & 5 & 35 & 5 & 45 & \multirow{4}{*}{4.94} & \multirow{4}{*}{$>0.2$} \\
\hline & $5-10$ & 24 & 111 & 13 & 148 & & \\
\hline & $>10$ & 0 & 18 & 1 & 19 & & \\
\hline & Total & 29 & 164 & 19 & 212 & & \\
\hline \multirow{4}{*}{ Family income per month } & $<500$ birr & 7 & 13 & 1 & 21 & \multirow{4}{*}{9.76} & \multirow{4}{*}{$<0.05$} \\
\hline & $500-1000$ birr & 5 & 47 & 3 & 55 & & \\
\hline & $>1000$ birr & 17 & 104 & 15 & 136 & & \\
\hline & Total & 29 & 164 & 19 & 212 & & \\
\hline \multirow{3}{*}{$\begin{array}{l}\text { Disease experience in the last } 2 \\
\text { weeks }\end{array}$} & Yes & 7 & 25 & 0 & 32 & \multirow{3}{*}{5.23} & \multirow{3}{*}{$<0.1$} \\
\hline & No & 22 & 139 & 19 & 118 & & \\
\hline & Total & 29 & 164 & 19 & 212 & & \\
\hline \multirow{4}{*}{ Number of meals per day } & 2 times & 3 & 2 & 0 & 5 & \multirow{4}{*}{13.36} & \\
\hline & 3 times & 23 & 139 & 13 & 175 & & $<0.01$ \\
\hline & $\geq 4$ times & 3 & 23 & 6 & 32 & & 0.01 \\
\hline & Total & 29 & 164 & 19 & 212 & & \\
\hline & Yes & 14 & 88 & 3 & 105 & & \\
\hline $\begin{array}{l}\text { Regular meal skipped in the } \\
\text { last } 2 \text { weeks }\end{array}$ & No & 15 & 76 & 16 & 107 & 9.76 & $<0.01$ \\
\hline & Total & 29 & 164 & 19 & 212 & & \\
\hline & Yes & 1 & 16 & 2 & 19 & & \\
\hline Contraceptive use & No & 28 & 148 & 17 & 193 & 1.26 & $>0.2$ \\
\hline & total & 29 & 164 & 19 & 212 & & \\
\hline & Break fast & 8 & 59 & 4 & 71 & & \\
\hline Usual meal & Lunch & 14 & 75 & 12 & 101 & 3.08 & $>0.2$ \\
\hline & Dinner & 7 & 30 & 3 & 40 & & \\
\hline & Total & 29 & 164 & 19 & 212 & & \\
\hline & $<4$ & 9 & 31 & 1 & 41 & & \\
\hline Minimum dietary diversity & $\geq 4$ & 20 & 133 & 18 & 171 & 6.05 & $<0.05$ \\
\hline & Total & 29 & 164 & 19 & 212 & & \\
\hline
\end{tabular}

Adolescent girls, as they are not children and not quite adults, are often not considered within the development agenda. This study found that the prevalence of underweight is $13.6 \%$ which is consistent with the national nutrition report which reports the prevalence of underweight was $14.4 \%[15]$. But it is contrary with the study from rural communities of Tigray. The study from the northern Ethiopia the prevalence of underweight was $26.6 \%[8,16]$. The reason for the difference in the prevalence may attribute from the difference in the settings. The northern study is community based crossectional study while the current study is institutional based study. The findings of this study contradict with a study from India (53\%), Bangladesh (50\%) and Nepal (36\%)[17]. This contradiction may result from the difference in socio demographic and economic characteristics. The other justification may result from the current concern of the Ethiopian policy towards nutrition.

The current study found that the prevalence of obesity and 
overweight is found $8.96 \%$ among adolescents. A comparable finding was reported from Addis Ababa which showed that the prevalence of overweight among primary school students in Addis Ababa was $7.6 \%$ [18]. However a study from India reported that the prevalence of obesity and overweight is $16.3 \%$.[19] The contradiction may result from the economic difference between Ethiopia and India. But this is an indicator of the occurrence of double burden malnutrition in the study area[19]

According to the national nutrition survey report only $72 \% \%$ of the adolescents have greater than four food groups from the total of 10 food groups in the last 24 hour recall[15]. However the prevalence of minimum dietary diversity was $80.7 \%$ in this study. The contradiction may result in difference in the methodology of the estimating the food groups .This study use the WHO food group classification which is the recommended one currently.

Almost one third reported having skipped a meal in the 2 weeks prior to the survey[15]. Study done in Addis Ababa also revealed that $140(13.7 \%)$ took lunch sometimes while $26(2.5 \%)$ never took lunch. Similarly, 219(21.4\%) of the students took dinner sometimes and 34(3.3\%) never took dinner all days of the week [20]. The prevalence of meal skipping in the current study was $49.53 \%$. The difference may result from the difference in the study settings.

This study found that the associated factors of nutritional status were family income, meal skipping in the last two weeks, number of meals per day and dietary diversity. But factors like place of residence, religion, and ethnicity, and family size, disease experience in the last 2 weeks, Contraceptive use, and type of usual meal were not found statistically significant. Study done in Kurukshetra among school adolescents girls showed occasional consumption of non vegetarian meals by the girls affected by socio economic status of the family [21]. But a study from northern Tigray reported that Place of residence is not associated with adolescent girls but family size is statistically associated with nutritional status of adolescents[16].

\section{Conclusion}

In conclusion, we have tried to assess the nutritional status by using BMI by measuring the weight and height of respondent. And then by using the Chi square test we found out the association between the risk factors of nutritional status of adolescents and their BMI.

Depending out the BMI the prevalence of under nutrition and over nitration were $13.68 \%$ and $8.96 \%$ respectively. Secondly, our results reveal evidence that under nutrition is the prevalent problem among these adolescents. So, programs to support adequate nutrition for adolescents could provide an opportunity for healthy transition from childhood to adulthood and could be an important step towards breaking the vicious cycle of intergenerational mal nutrition. Regular meal skipped in the last two weeks, number of meals eaten per day, family income and minimum dietary diversity were found to be an important determinant and showed a significant association with the nutritional status of adolescents. On other hand, residence, religion, ethnicity, family size, disease experience in the last two weeks, contraceptives and usual meals were found to be variables those haven't association with the nutritional status of the adolescents.

\section{References}

[1] Kleigman, B., Jenson,Staton (2004). Nelson Text Book of Pediatrics.

[2] Agarwal KN, Tripathi AM, Sen S Kaliyar GP (1999). Physical growth and adolescence. Ind. Paediatr. 11, 93-97.

[3] Giuseppina D (2000). Nutrition in Adolescence. Pediatrics in Review. 21(1),32-33.

[4] Kanade AM, Joshi SB, Rao S (1999). Undernutrition and adolescent growth among rural Indian boys. Indian Pediatrics, $36,145-156$.

[5] Singh N, Mishra CP (2001). Nutritional status of adolescent girls of a slum community of Varanarsi. Indian J. Public Health, 45,128-134.

[6] World Bank (2006). Repositioning Nutrition as Central to Development: A Strategy for Large-Scale Action. Washington: The International Bank for Reconstruction and Development/The World Bank.

[7] Alam N., et al.( 2010). Nutritional Status, Dietary Intake, and Relevant Knowledge of Adolescent Girls in Rural Bangladesh. Journal of Health Population Nutrition, 28(1), 86-94.

[8] Mulugeta A. et al. (2009).nutritional status of adolecent girls from communities of Tigray, northern Ethiopia. Ethiopian journal of health development.23(1),5-11.

[9] Venkaiah K, Damayanti K, Nayak MU, Vijayaraghavan K (2002). Diet and nutritional status of rural adolescents in India. Eu. J.Clin. Nutr.,56,1119-1125.

[10] Woodruff BA, Duffield A (2002). Anthropometric assessment of nutritional status in adolescent population in humanitarian emergencies. Eu J Clin Nutr, 56,1108-1118.

[11] Brabin L, Brabin BJ (1992). The cost of successful adolescent growth and development in girls in relation to in relation to iron and vitamin A status. Am J Clin Nutr,55,955-958.

[12] Steketee RW (2003). Pregnancy, Nutrition and Parasitic Diseases. J. Nutr; 133:1661S-1667S.

[13] WHO, Expert Committee Endorsed The Use Of BMI For Assessing Thinness In Adolescent. 2006.

[14] Woodruff BA, Duffield A (2002). Anthropometric assessment of nutritional status in adolescent population in humanitarian emergencies. Eu J Clin Nutr,56,1108-1118.

[15] Leenstra T, Petersen LT, Kariuki SK, Oloo AJ, Kager PA, Kuile FO (2005). Prevalence and severity of malnutrition and age at menarche; cross sectional studies in adolescent schoolgirls in western Kenya. Eur J Clin Nutr,59,41-48.

[16] Mulugeta A., et al., (2009). Nutritional Status of Adolescent Girls from Rural Communities of Tigray, Northern Ethiopia .Ethiopian Journal of health developmemt. 23(1), 511. 
452 Ahmed Yasin Mohammed and Tomas Benti Tefera: Nutritional Status and Associated Risk Factors Among Adolescents Girls in Agarfa High School, Bale Zone, Oromia Region, South East Ethiopia

[17] WHO (2006). Adolescent Nutrition: A Review of the Situation in Selected South-East Asian Countries.

[18] Zeleke, A. and F. Enquasillase (2009). Prevalence of childhood and adolescent overweight and obesity among elementary school students in Addis Ababa: Double burden of malnutrition in Ethiopia. AAU electronics library.

[19] WHO (2000). Adolescent Nutrition: A Review of the Situation in Selected South-East Asian Countries.

[20] Yoseph Gebreyohannes, Solomon Shiferaw, Balem Demtsu,
Gessessew Bugssa. Nutritional Status of Adolescents in Selected Government and Private Secondary Schools of Addis Ababa, Ethiopia. International Journal of Nutrition and Food Sciences. Vol. 3, No. 6, 2014, pp. 504-514. doi: 10.11648/j.ijnfs.20140306.13

[21] Gurpreet Arora, G. K. Kochar, Gunjan Soni. Nutritional Awareness and Status of Adolescent Girls Studying in Schools of Urban and Rural Areas of District Kurukshetra. Journal of Food and Nutrition Sciences. Vol. 3, No. 3, 2015, pp. 126-130. doi: 10.11648/j.jfns.20150303.18 